\title{
Use of Real-Time Multisatellite and Radar Data to Support Forest Fire Management
}

\author{
Gary L. Hufford, H. Lee Kelley, and William Sparkman \\ NOAA/NWS Alaska Region, Anchorage, Alaska \\ RAYMOND K. MOORE \\ Litton/PRC Inc., Anchorage, Alaska
}

(Manuscript received 10 April 1997, in final form 12 March 1998)

\begin{abstract}
Combined digital data from multiple satellites and Doppler radar can provide fire weather meteorologists and resource managers with accurate information on forest fire location, intensity, growth, smoke plumes, and associated mesoscale weather. An integrated application using real-time satellite and radar is described for the Miller's Reach forest fire that occurred in south-central Alaska in June 1996. Generated data and products were made available immediately on-scene via point-to-point high-speed portable satellite communications. This fire consumed over 15000 ha and destroyed 344 structures.
\end{abstract}

\section{Introduction}

Early detection and continual monitoring of forest fires is critical to forest fire decision makers. Timely fire location information, along with accurate weather conditions, provides the basis for appropriate suppression response. In Alaska, most of the state is wilderness where the surface observational network is very sparse. There exist many areas of over $2000 \mathrm{~km}^{2}$ that have no human observers. Monitoring of wildfires is still conducted using expensive aircraft reconnaissance flights. Periods of heavy smoke and/or inclement weather can hamper the collection of important information on the fires. A viable means of obtaining real-time information about forest fires, especially in these wilderness regions, is the use of multiple types of remote sensing. A challenge is how to deliver real-time products to decision makers at the remote fire scene.

In Alaska, there are two sources of remote sensing information that can offer a cost-effective means of gaining detailed information on the spatial and temporal variability of forest fires, as well as their smoke production and associated weather. These are satellites and Doppler radars. In addition, a portable workstation has been developed that can be deployed at any location, at any time, which utilizes satellite-based, high-speed communications to deliver real-time products at the fire scene.

Corresponding author address: Gary L. Hufford, National Weather Service, 222 W. 7th Ave., \#23, Anchorage, AK 99513-7575.

E-mail: Gary.Hufford@noaa.gov
There are a number of polar and geostationary satellites with unique sensors that can provide temporal and spatial data about Alaska forest fires as well as the associated weather. The National Weather Service (NWS) in Alaska ingests real-time digital data from the following satellite sensors using a high resolution image processing system:

- National Oceanic and Atmospheric Administration (NOAA) Advanced Very High Resolution Radiometer (AVHRR),

- GOES-9 imager,

- Defense Meteorological Space Program (DMSP) Operational Linescan System (OLS),

- Total Ozone Mapping Spectrometer.

In addition, Synthetic Aperture Radar (SAR) digital data from the European ERS-1 and -2 and Canadian RADARSAT are obtained near real time via a high-speed communications line from the University of AlaskaFairbanks SAR downlink facility.

The NWS operates seven Weather Surveillance Radar-1988 Doppler (WSR-88D) radars within Alaska. One of the radars is located about $90 \mathrm{~km}$ south-southwest of Anchorage. This $10-\mathrm{cm}$ radar not only detects and measures the power backscattered by a target (reflectivity), but also measures the radial velocity of a target moving toward or away from the radar. The radar has a detection range of approximately $460 \mathrm{~km}$ for reflectivity and a radial velocity and spectrum width capability out to $230 \mathrm{~km}$ (Klazura and Imy 1993).

The NWS has designed the Alaska Incident Response System (AIRS) for use in a remote environment by utilizing the portability of a powerful laptop and two-way 
point-to-point satellite communications. The AIRS uses a 1-m satellite dish configured for high-speed data flow at $56 \mathrm{~kb} \mathrm{~s}^{-1}$, a PC running UNIX, a router, a modem, and a base station computer located at the NWS Alaska Region Headquarters (Dragomir et al. 1997). AIRS is used to transmit, receive, and display National Centers for Environmental Prediction (NCEP) numerical model output, forecasts, and observational data including satellite, radar, and upper air soundings.

This paper will look at an integrated application of real-time multisatellite and WSR-88D radar data to support the fire weather meteorologists and resource managers on-scene during forest fires. The application was tested on the 15 128-ha Miller's Reach forest fire that occurred in south-central Alaska in June 1996.

\section{Unique attributes of different satellite data types for fires}

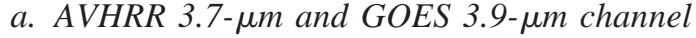

Forest fire temperatures commonly range from 500 to $1000 \mathrm{~K}$ (Robinson 1991). The most suitable emission band for fire detection is in the shorter-wavelength infrared channels based on Wien's law, which states that the wavelength of maximum radiation intensity shifts toward shorter values with increasing temperature. Both the NOAA polar orbiters (POES) and Geostationary Operational Environmental Satellites (GOES) have infrared channels (3.7 $\mu \mathrm{m}$ and $3.9 \mu \mathrm{m}$, respectively) that respond rapidly to hot spots. The channels are so sensitive that they can detect at increments smaller than the field of view (Kaufman et al. 1990; Weaver et al. 1995). This response to detect hot spots that are smaller than imagery resolution makes these short-wavelength channels most useful in monitoring and tracking forest fires. Resolution of the POES is $1.1 \mathrm{~km}$ at nadir, while GOES is about $9 \mathrm{~km}$ at $60^{\circ} \mathrm{N}$ latitude.

There are some limitations using shorter-wavelength infrared from the NOAA satellites for the detection and growth of fires. One shortcoming of the AVHRR 3.7$\mu \mathrm{m}$ and GOES 3.9- $\mu \mathrm{m}$ channels is that they saturate at 320 and $335 \mathrm{~K}$, respectively, with anything warmer being offscale. Thus the absolute temperatures of a fire cannot be determined by these sensor channels. The actual temperature value sensed by the satellite can also be affected by fuel type and moisture, density of combustibles, obscuration by smoke or clouds, overstory canopy, blockage by steep terrain due to viewing angle, and the amount of fire occurring within each pixel. The extent of fire in a pixel can be easily overestimated because a pixel can become saturated even if only a small portion is actually occupied by fire. However, Chuvieco and Martin (1994) have demonstrated that one can still detect a fire and monitor its growth using hot pixels, saturated or not, by incorporating differencing and Geographical Information System (GIS) overlay techniques.
The 3.7-3.9- $\mu \mathrm{m}$ channels are also affected by a strong reflectance component during daylight, making interpretation difficult. This problem can be minimized by deconvolution of the reflectance from the emitted using an inverse Plank computation (Henderson-Sellers 1984). Another limitation is that the AVHRR 3.7- $\mu \mathrm{m}$ channel is often contaminated by variable sensor noise degrading the results. This noise can be corrected by using a Wiener filtering technique developed by Simpson and Yhann (1994). The AVHRR 3.7- $\mu$ m data used in this paper have been corrected using those techniques.

GOES-9 is positioned approximately $35800 \mathrm{~km}$ above the equator at $135^{\circ} \mathrm{W}$ longitude and has five imaging channels including $3.9 \mu \mathrm{m}$. The high signal-tonoise ratio provides quality data to at least a $70^{\circ}$ viewing angle. This ensures high quality coverage over southern Alaska every $15 \mathrm{~min}$, providing a timely detection system for large hot spots.

\section{b. AVHRR and DMSP visible channels}

AVHRR visible $(0.55-0.68 \mu \mathrm{m})$ imagery has long been used to identify smoke plumes associated with forest fires (Kaufman et al. 1990). Optical thickness, particle size, and single-scattering albedo have been determined using this shortwave band data. Knowing the area affected by smoke can be used by air quality agencies to issue potential health warnings. However, AVHRR visible data can only be used for daylight techniques.

The OLS is the primary sensor for DMSP. The system is designed to produce constant high-resolution imagery $(0.3 \mathrm{~km})$ as opposed to accurate radiometry and, therefore, differs significantly from the NOAA AVHRR system in many details. There are only two imaging channels: visible, 0.4-1.1 $\mu \mathrm{m}$; and thermal infrared, 10-12 $\mu \mathrm{m}$. The daytime visible imagery from DMSP, like AVHRR visible, can be readily used to detect and track smoke originating from forest fires. A unique capability of the DMSP visible channel is its ability to produce a nighttime visible image. The channel incorporates a photomultiplier tube and filter to take into account the difference between the solar and lunar reflective spectrum.

The nighttime visible image distinguishes clouds easily and provides a means of detecting fires and tracking smoke plumes similar to daylight techniques. The nighttime data used in conjunction with the AVHRR 3.7- $\mu \mathrm{m}$ data provides a detailed look at the temporal and spatial development of a fire and its smoke patterns at night.

\section{c. SAR imagery}

SAR is an active microwave sensor that sends pulses of energy and measures various characteristics of the reflected radiation whose intensity is directly proportional to the radar backscatter. SAR has the capability to sense through the clouds with a spatial resolution on 


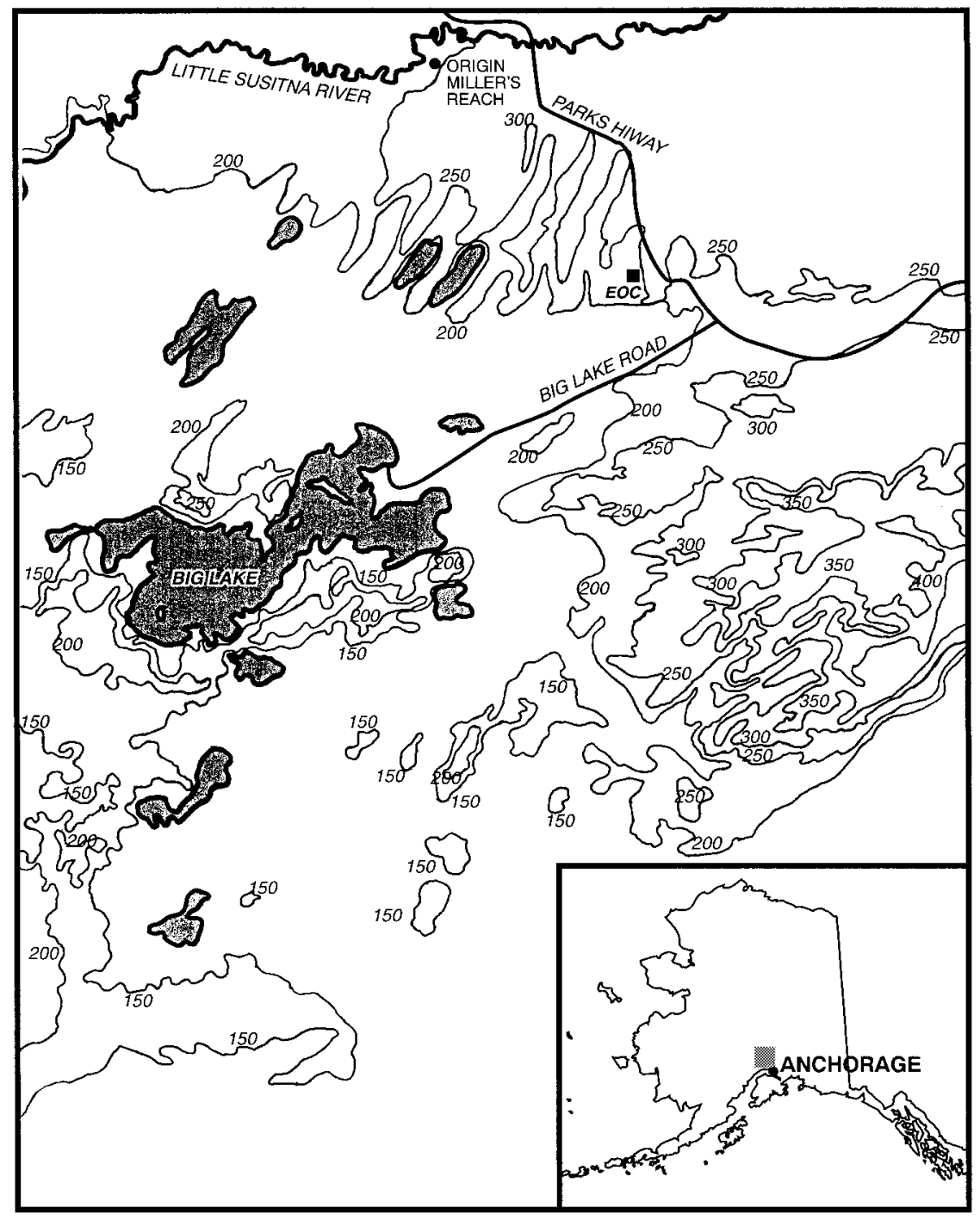

FIG. 1. A map of the Big Lake region of south-central Alaska showing the Miller's Reach fireaffected areas: "O" indicates the origin of the fire. Topography is in ft. EOC shows the location of the Emergency Operations Center.

the order of meters. The major use of ERS-1 SAR in the investigation of the Miller's Reach forest fire is to obtain an accurate estimate of the fire burn area over time. SAR imagery products are calibrated, corrected for antenna pattern, and range spreading loss. Forest areas appear uniform and dark. Areas after a fire appear light gray to bright white. A study of fires in Alaska showed that some of this enhanced brightness was due to increased ground moisture rising to the surface after the fire (Kasischke et al. 1992).

\section{Features of the WSR-88D for fires}

Doppler radar detects backscattered electromagnetic energy and computes reflectivity that is proportional to the target's diameter raised to the sixth power. This can be expressed as

$$
P_{\mathrm{r}}=R_{\mathrm{c}} K^{2} Z / R^{2},
$$

where $P_{\mathrm{r}}$ is the radar echo power received, $R_{\mathrm{c}}$ is a radar constant containing the wavelength relations specific to the radar, $R$ is the range of the target, $K^{2}$ is the refractive index factor, and $Z$ is the target reflectivity factor (Probert-Jones 1962). Because the radar echoes are so strongly dependent on the size of the particles, the return signal detected by the radar is dominated by larger particles suspended in the cloud. Thus particle size and concentration can be estimated in the smoke cloud.

Radial velocities of the particles in the cloud can also be estimated using the WSR-88D. As the target moves, 


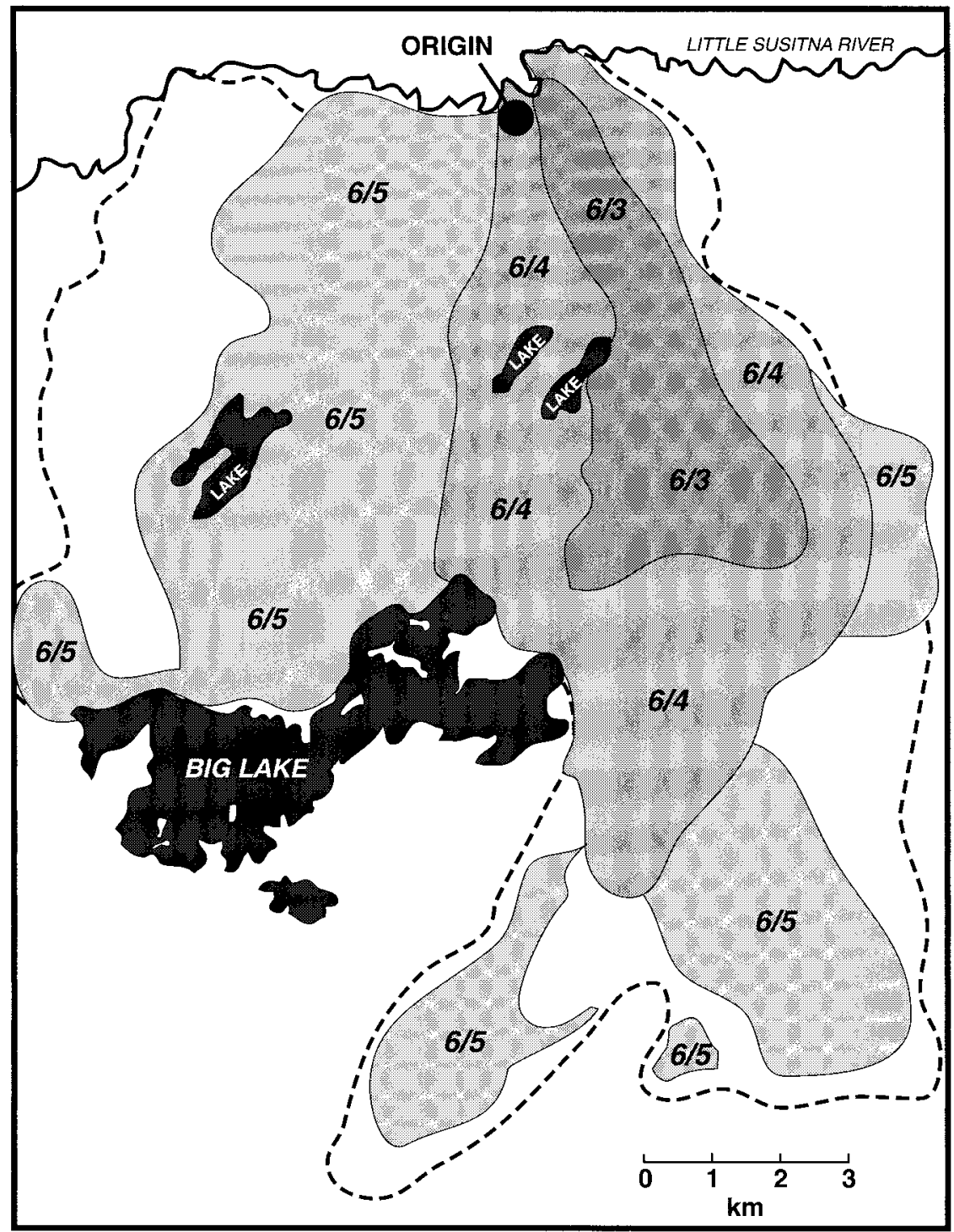

FIG. 2. Map of the Miller's Reach fire showing fire-affected areas for each day from 3 to 5 June 1996. Dashed line shows the final boundary of the total burned area.

there is a shift in the phase of the electromagnetic wave by an amount that is proportional to its speed. Thus any movement toward or away from the radar can be measured.

\section{Evolution of the Miller's Reach fire}

Drought conditions began over south-central Alaska in September 1995. The area received less than $30 \%$ of the normal precipitation for the 1995/96 winter. Almost the entire winter snowfall occurred over a 10-day period in February 1996. Without a snow cover, the ground froze down to nearly $3 \mathrm{~m}$. During spring thaw, the small amounts of snow present on the ground melted and ran off into neighboring streams instead of percolating into the still frozen ground. Drought conditions with very low humidities $(<25 \%)$ continued through June 1996.

On 2 June a small fire started at 1600 local standard time (LST) in an area known as Miller's Reach, approximately $50 \mathrm{~km}$ north of Anchorage, Alaska (Fig. 1). The fire origin was just north of a very large, popular recreational area known as Big Lake that contains over 1000 dwellings. The area consists of mostly flat terrain with a few low rolling hills ( $<80 \mathrm{~m}$ high) and many lakes. The forest in the area was dominated by black spruce, but also contained birch, alder, white spruce, and cottonwood. There was also a very thick undergrowth that made it easy for a fire to creep and for hot spots to remain well after the main fire passed through the area. The fire was quickly contained by 2200 LST 


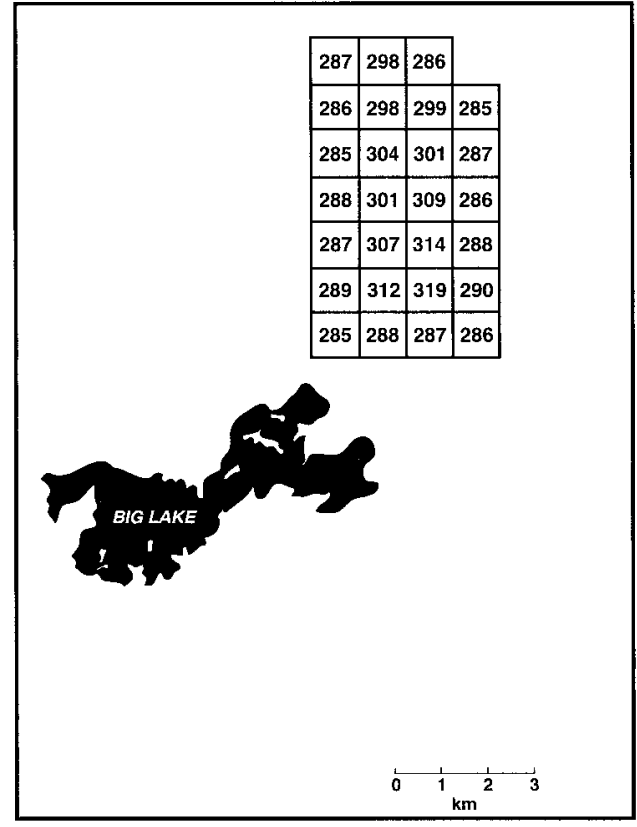

FIG. 3. Brightness temperatures $(\mathrm{K})$ of the Miller's Reach fireaffected pixels and their immediate neighbors from NOAA AVHRR 3.7- $\mu \mathrm{m}$ image, 2034 LST 3 June 1996.

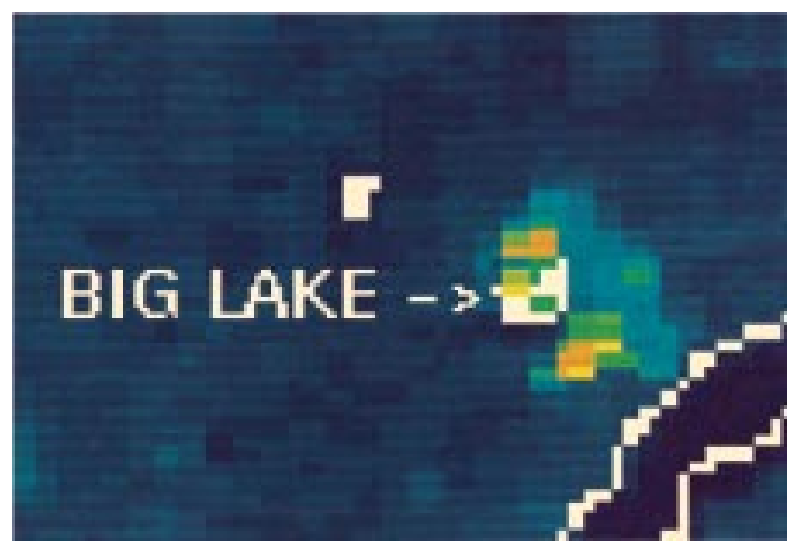

FIG. 5. NOAA AVHRR 3.7- $\mu$ m image, 0738 LST 5 June 1996, showing fire-affected pixels and their immediate neighbors. False color table applied with blue cold and red hot.

after burning about 25 ha. A few small hot spots were left to be cleaned up the next day. The weather forecast called for light winds and clear skies. It should be noted that there were no weather observation systems in the Miller's Reach area. The nearest telemetered site was located in the small town of Willow, about $25 \mathrm{~km}$ northwest and not representative of the weather conditions at the fire's origin. A manual observation site was lo-

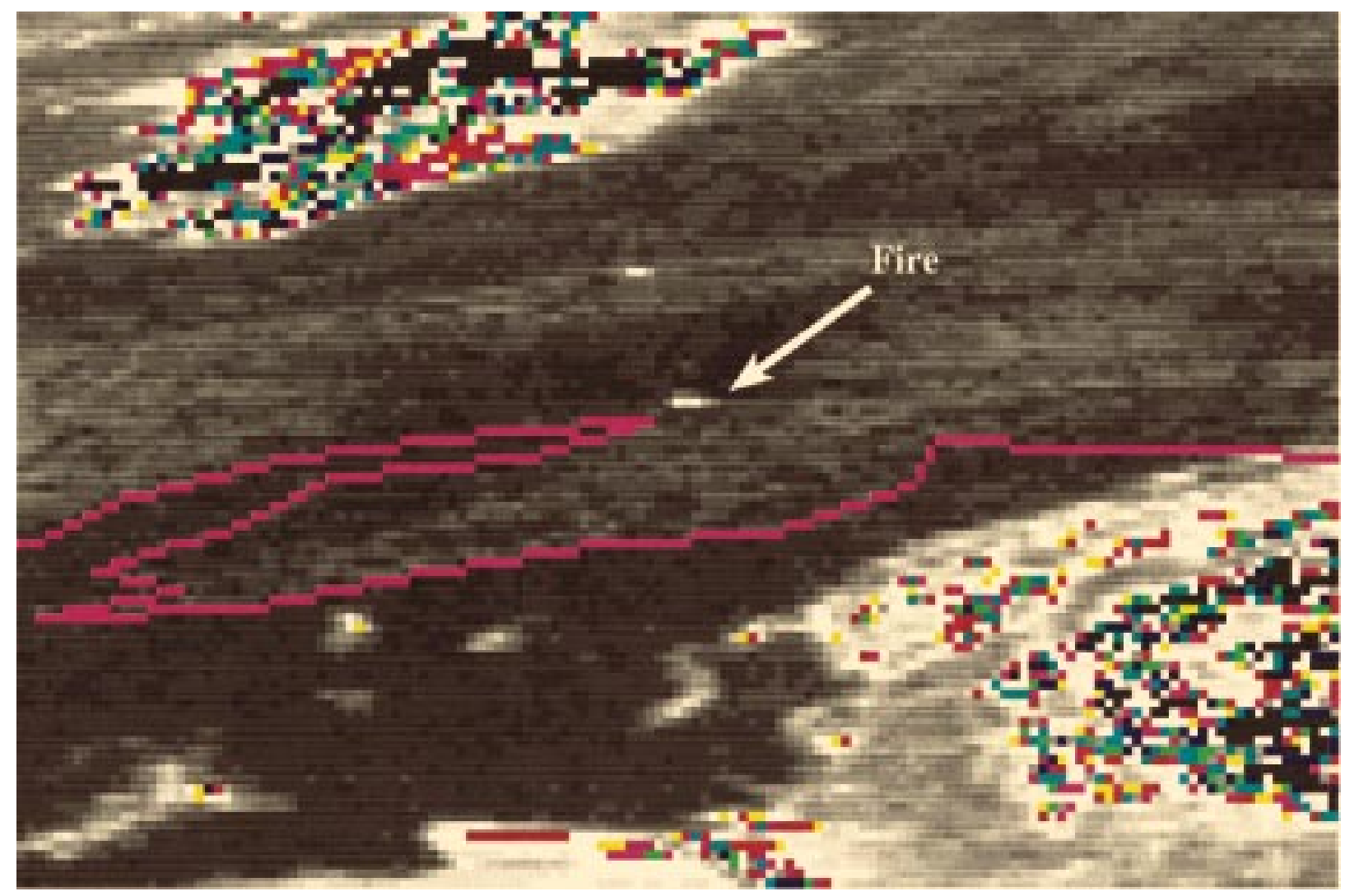

FIG. 4. GOES-9 3.9- $\mu$ m image, 0730 LST 5 June 1996, showing white hot spot north of Big Lake, Alaska. 


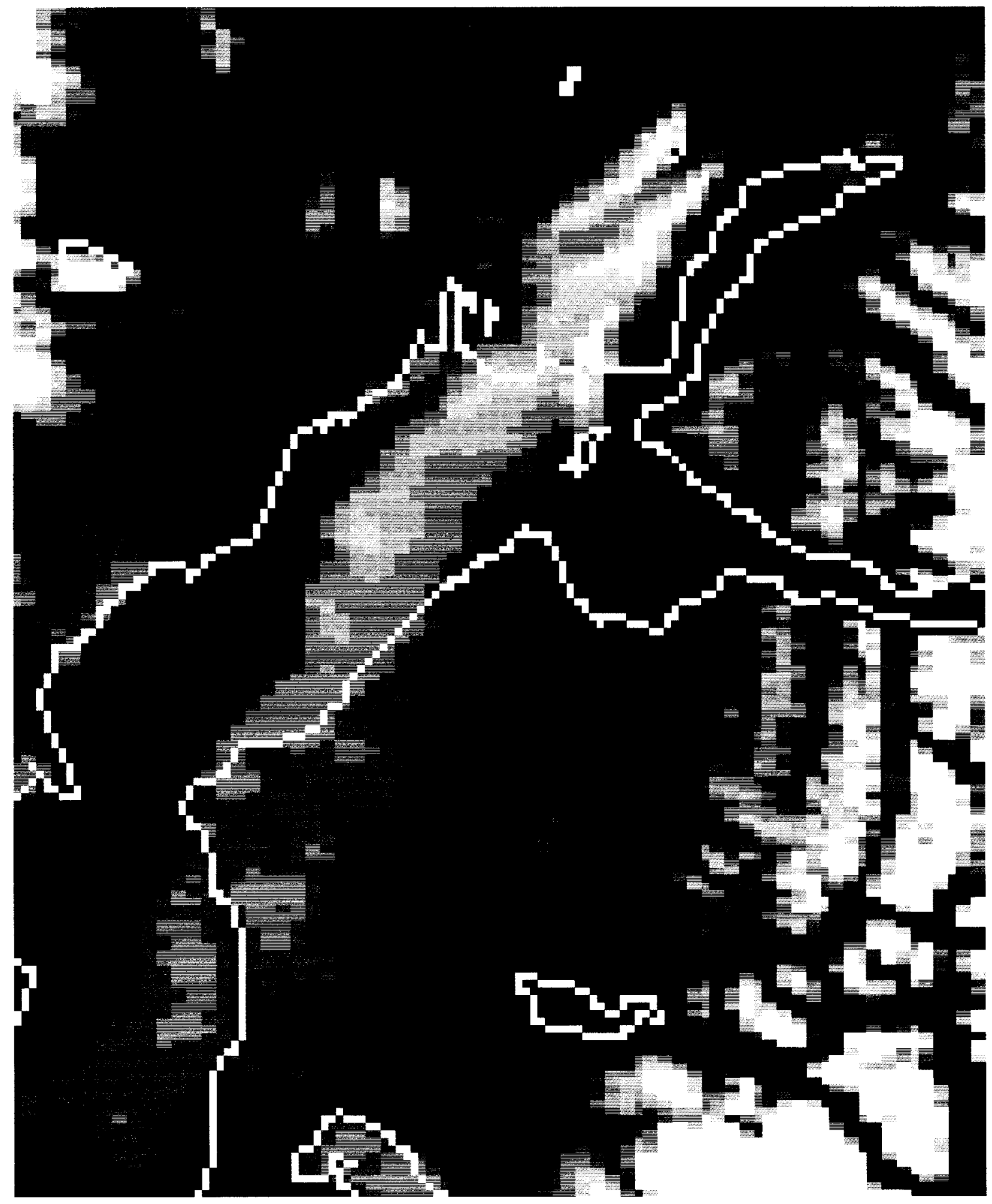

FIG. 6. NOAA AVHRR visible image, 0738 LST 5 June 1996, showing smoke plumes from the Miller's Reach fire. 


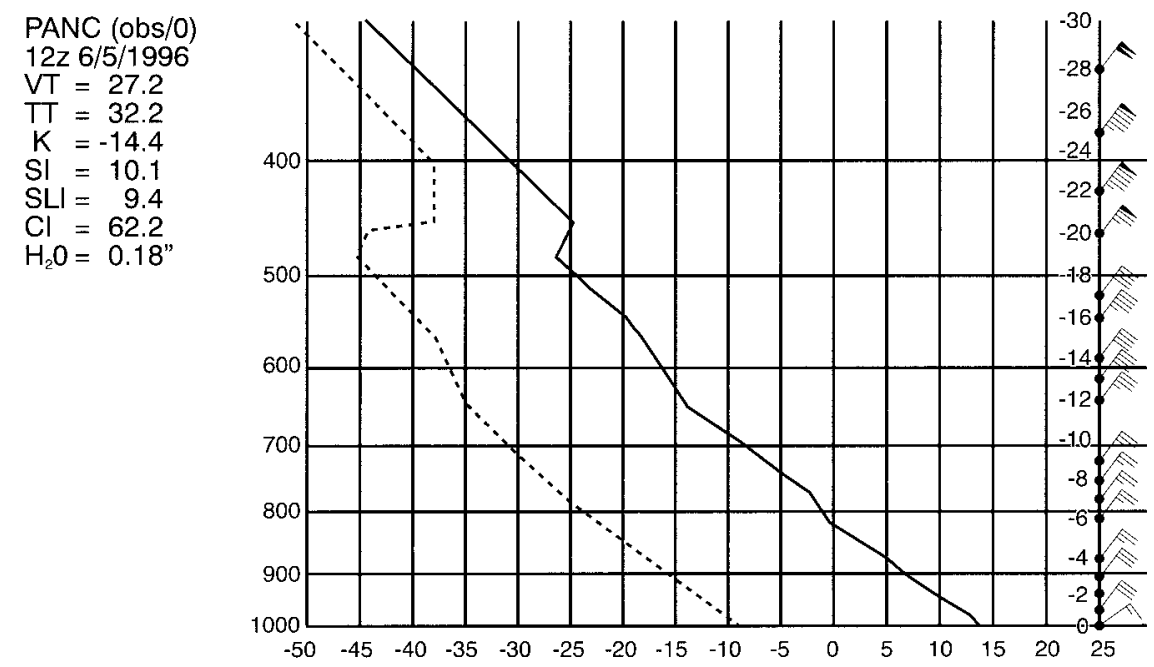

FIG. 7. Anchorage temperature sounding at 1200 UTC 5 June 1996. Pressure is labeled in $\mathrm{mb}$ and winds in $\mathrm{m} \mathrm{s}^{-1}$.

cated at the Alaska Department of Natural Resources Office in Big Lake (10 km south of Miller's Reach), but the data is not routinely provided to the NWS.

On 3 June, the day began at Big Lake with fair skies and light winds $\left(2 \mathrm{~m} \mathrm{~s}^{-1}\right)$ from the southwest. By 1700 LST, maximum temperature reached $22^{\circ} \mathrm{C}$ with relative humidity between $30 \%$ and $40 \%$ (Alaska Department of Natural Resources 1996). At 1920 LST, the winds suddenly switched out of the northwest with the passage of a cold front and increased to $15 \mathrm{~m} \mathrm{~s}^{-1}$. Temperature and relative humidity dropped to $18^{\circ} \mathrm{C}$ and $20 \%$. The fire at Miller's Reach reignited and rapidly spread out of control. Because of the drought, the black spruce had been chronically moisture stressed and became the primary carrier for a crown fire. Over the next $4 \mathrm{~h}$ the fire spread south $7.2 \mathrm{~km}$ in a very narrow finger, reaching the Big Lake area (Fig. 2). At 0000 LST, the winds then shifted around to the southwest causing the fire to burn back on itself.

On 4 June, weather conditions indicated that there would be continuous danger for fires. A red flag warning was issued in the morning by the fire weather meteorologist at the Anchorage Weather Service Forecast Office due to expected warm temperatures, gusty north winds, and low humidities $(<17 \%)$. The Alaska Fire Service (AFS) requested an incident meteorologist for their Emergency Operation Center (EOC), located in a local high school near the fire origin. By midmorning, strong northerly winds, with gusts reported over $15 \mathrm{~m} \mathrm{~s}^{-1}$, again fanned the fire into the canopies of the trees and the fire raced south in the crowns. By that afternoon, the fire had reached the northeast shore of Big Lake. A total of over 4850 ha had been scorched and numerous dwellings lost. For the next few days, high winds continued to plague suppression efforts.

By the morning of 5 June, the fire had split around Big Lake, burning toward the west along the north shore and to the south along the east shore driven by the winds (Fig. 2). The fire was declared a disaster area by the governor. By 6 June, over 1200 firefighters were fighting the fire. The fire was finally contained on 10 June. Five days later, 15 June, the fire was declared under control. Over 15100 ha had burned and 344 structures had been destroyed (Fig. 2). The fire effects included millions of dollars in destroyed property, poor air quality over much of south-central Alaska, significant long-term economic loss in the Big Lake area, and closures of the main road and rail corridors between Anchorage and Fairbanks.

\section{Real-time satellite-radar observations and calculations}

Animated 15-min GOES infrared imagery was used to detect the initial Miller's Reach fire. High-resolution AVHRR images were chosen in which the viewing angle of the fire site was less than $30^{\circ}$ from nadir to minimize the effect of cross-track distortion. At the same time, Doppler radar data were collected to examine the smoke plumes generated by the fire. Products generated from these integrated datasets were made available in real time to fire weather meteorologists and resource managers at the EOC via the AIRS portable system.

To demonstrate the value of the real-time integrated data during the Miller's Reach fire, two specific days are examined in detail: 3 June and 5 June. On 3 June, the fire was still small (900 ha) and in its early stages. On 5 June, more than $40 \%$ of the total area burned. Viewing conditions on both days were similar to that during most of the fire event-clear skies. Both days were plagued with high, shifting winds.

\section{a. 3 June}

As described above, the fire reignited on 3 June following a wind shift that occurred at 1920 LST. At 2000 


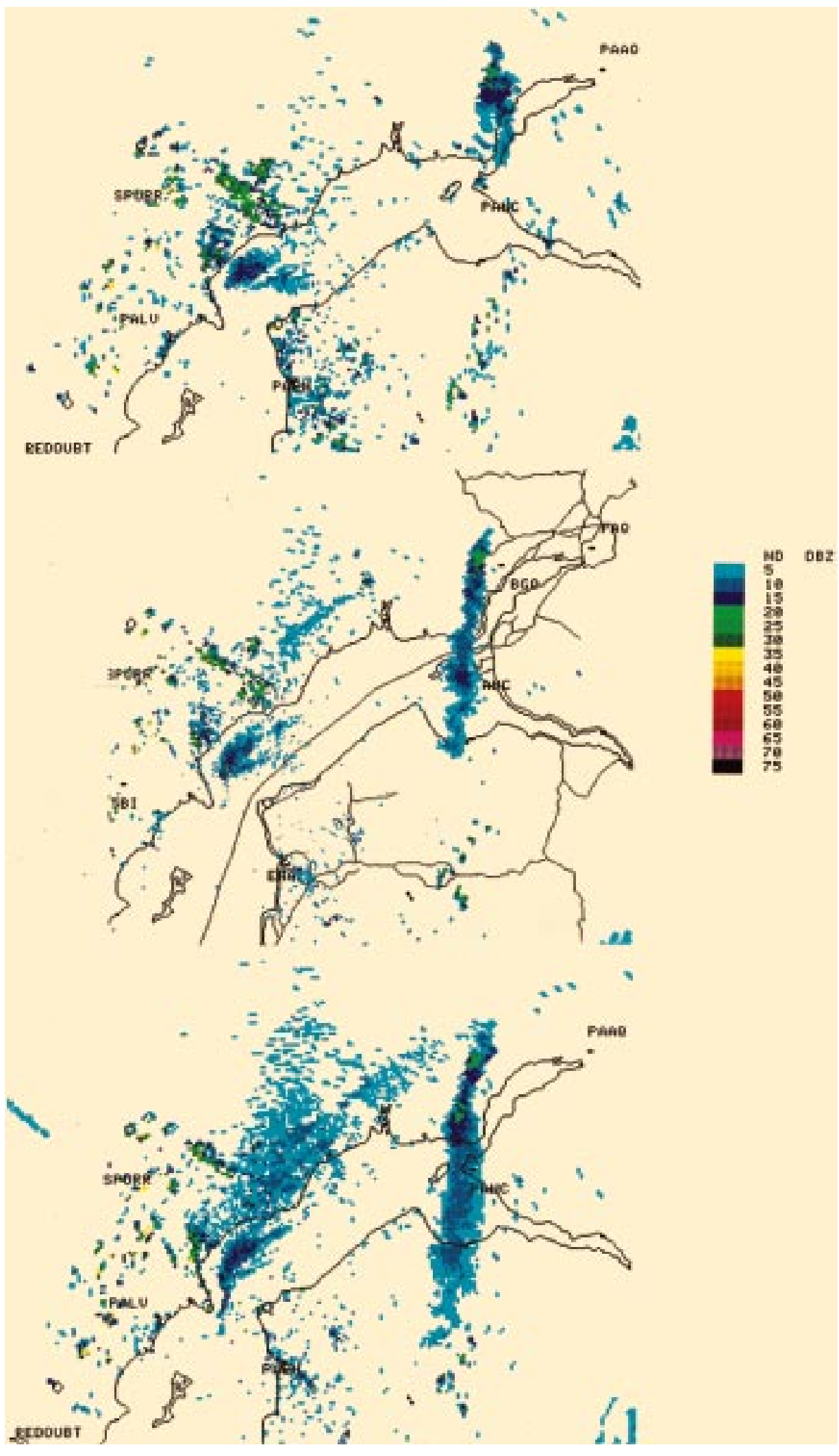

FIG. 8. Radar reflectivity from WSR-88D at Kenai at (a) 0435, (b) 0538, and (c) 0738 LST 5 June 1996. Note the high reflectivities west of the Miller's Reach fire smoke plume are from chaff dropped during a military exercise. 


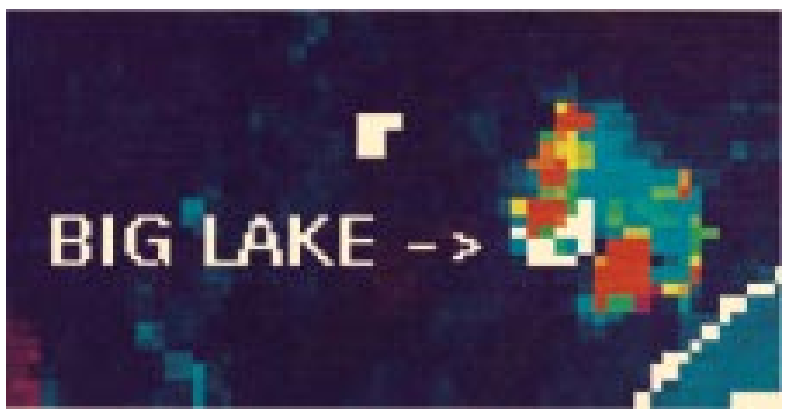

FIG. 9. NOAA AVHRR 3.7- $\mu \mathrm{m}$ image, 0918 LST 5 June 1996, showing fire-affected pixels and using a false color table (red $=$ hot, blue $=$ cold $)$.

LST, a GOES 3.9- $\mu \mathrm{m}$ image indicated the presence of a hot spot with a brightness temperature of $300 \mathrm{~K}$ in the fire area. At 2034 LST, an AVHRR 3.7- $\mu$ m image, using an inverse gray-shade table, showed a dark hot spot $4 \mathrm{~km}$ long and 1-2 km wide in the Miller's Reach area (Fig. 3). This hot spot was aligned primarily northsouth. Brightness temperature values ranged from 298 to $319 \mathrm{~K}$ for the hot spot pixels. Adjacent pixels in the image averaged $284 \mathrm{~K}$ and were considered background temperature. An examination of a GOES-9 3.9- $\mu \mathrm{m}$ image from 2345 LST showed that the hot spot had increased in size and that brightness temperatures ranged from 301 to $304 \mathrm{~K}$. Subsequent GOES imagery showed the hot spot continued to grow for another hour and a quarter (0100 LST 4 June). At that time, six pixels were being directly affected by the fire. Brightness temperatures ranged from 296 to $324 \mathrm{~K}$. Adjacent pixels averaged $279 \mathrm{~K}$.

The AVHRR 3.7- $\mu \mathrm{m}$ image was superimposed onto a geographical map using GIS techniques. Differences in temperatures from the hot spot to the background were at least $15 \mathrm{~K}$, significantly higher than sensor noise level of $1.5 \mathrm{~K}$ for the AVHRR (Kidwell 1995). The 298$\mathrm{K}$ pixels in the image were assumed to be postburn area still smoldering. A northern $298-\mathrm{K}$ pixel abutted against the Little Susitna River, near the origin of the fire. The highest pixel temperature (319 K) was located at the southern end of the hot spot, at the head of the fire. This image was observed by the satellite at a time about halfway through a period in which the fire raced over $7 \mathrm{~km}$ in $4 \mathrm{~h}$ through the crowns of the trees. Winds were reported greater than $15 \mathrm{~m} \mathrm{~s}^{-1}$ with the smoke advecting southward, minimizing any smoke obscuration over the fire itself. Estimation of the geographical extent of the fire in this image was made by assuming complete burn in each pixel except for the three pixels associated with the leading fire front. Here the fire was probably burning in a narrow strip at 800-1000 K, which would have been sufficient to saturate the entire pixel. Adjusting for the fire front, the estimation of the extent of the fire was about 900 ha.

\section{b. 5 June}

An AVHRR 3.9- $\mu \mathrm{m}$ image at 0533 LST showed three distinct but small hot spots. However, this image appeared to have smoke over the fire area, possibly contaminating the brightness temperatures. A GOES-9 3.9$\mu \mathrm{m}$ image at $0530 \mathrm{LST}$ did indicate a discernible hot spot. By 0730 LST, a GOES 3.9- $\mu \mathrm{m}$ image did show a hot spot, which continued to grow through the day (Fig. 4). An AVHRR 3.7- $\mu \mathrm{m}$ image from 0738 LST showed two larger, distinct areas containing hot spots, one to the north $(\max 310 \mathrm{~K})$ and one to the southeast (max $307 \mathrm{~K}$ ) of Big Lake. A very small hot spot (two pixels) was identified northeast of Big Lake. Maximum brightness temperature was $304 \mathrm{~K}$. A number of pixels averaging 290-297 K likely represented some of the postburn area (Fig. 5). Two "warm" pixels (290 and 293 $\mathrm{K})$ were observed over Big Lake itself in the imagery. These were false detections probably resulting from the ambiguous thermal signal produced by the presence of water and edges of the smoke (Lee and Tag 1990). A visible image from the same pass showed a smoke plume from the northern fire advecting south directly over the lake (Fig. 6). Pixels adjacent to the hot spots averaged $284 \mathrm{~K}$, a difference of at least $6 \mathrm{~K}$ between background and the hot spots.

The lower brightness temperatures of the hot spots observed at 0738 LST compared to the night of 3 June are thought to represent the suppressed state that fires enter early in the morning. The GOES imagery also showed the hot spot receding both in size and intensity during the early morning of 5 June. This reduced intensity is due to light winds, a nocturnal inversion, minimum surface air temperatures, and maximum relative humidities. The 1200 UTC (0300 LST) sounding for Anchorage, about $15 \mathrm{~km}$ south of the fire, showed a surface temperature of $12^{\circ} \mathrm{C}(285 \mathrm{~K})$, a relative humidity of $52 \%$, and surface winds of about $8 \mathrm{~m} \mathrm{~s}^{-1}$ (Fig. 7). An inversion was not evident. It appears the Anchorage sounding is not completely representative of conditions at the fire scene. AFS personnel on scene reported that smoke rose, then flattened out and spread horizontally, indicating an inversion the morning of 5 June (AFS 1996, personal communication).

The WSR-88D data also indicated the suppressed state of the fire on the morning of 5 June (Figs. 8a-c). Reflectivity data at 0435 LST showed two short plumes extending southward from north and southeast of the lake. However, by 0533 LST, only a single, long plume is seen. At $0738 \mathrm{LST}$, the data show this plume extending over $115 \mathrm{~km}$ to the south of the fire. The large plume is probably a combination of two plumes associated with the two separate burn areas, but may not be detectable as such on Doppler radar due to viewing angle. The extent of the smoke plumes in the radar data at 0435 LST suggests that the fire was most reduced in activity at that time.

The total extent of the burn area in the imagery at 


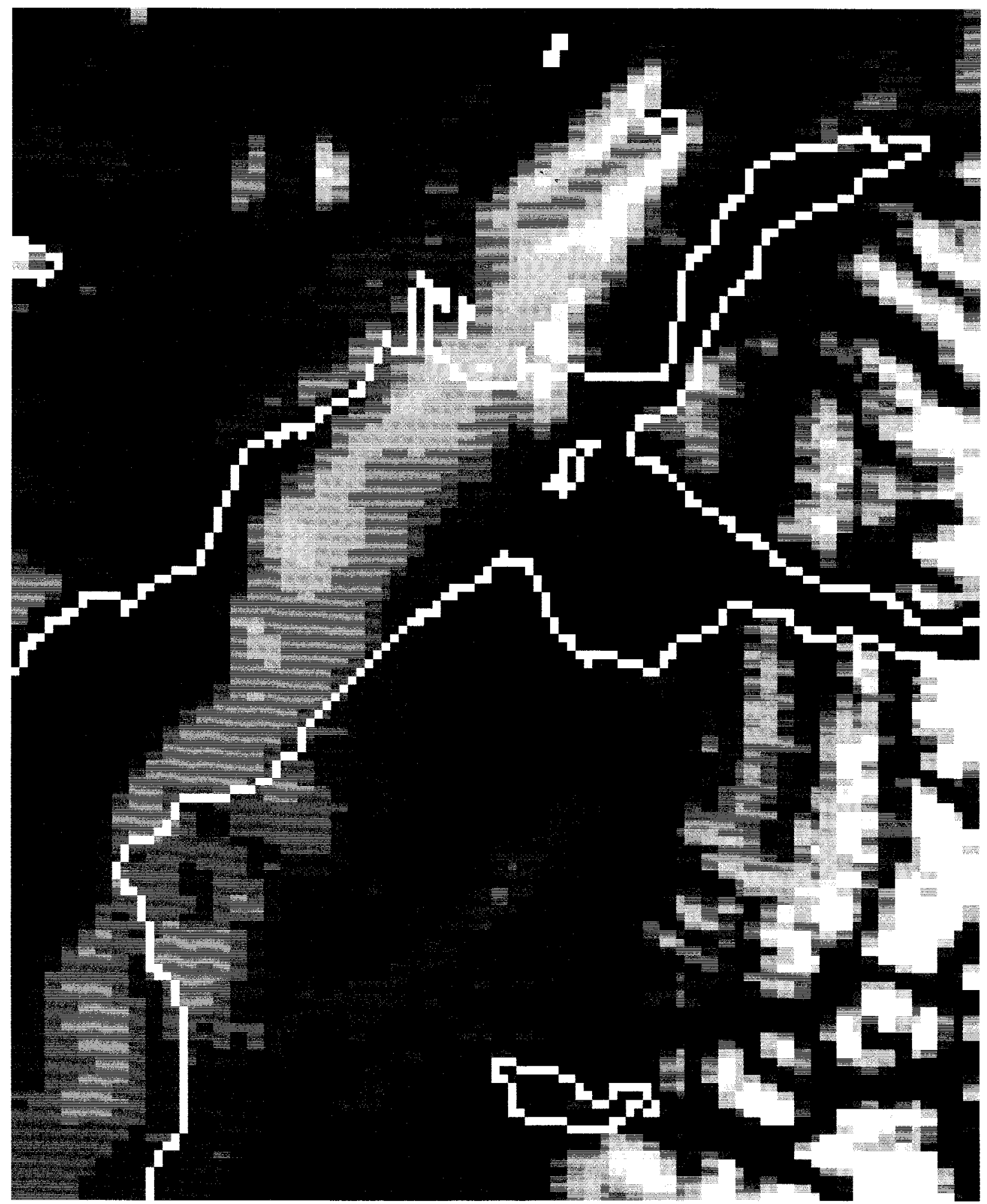

FIG. 10. DMSP visible image, 0925 LST 5 June 1996, showing smoke plume from Miller's Reach fire extending south over Anchorage, Alaska. 
0738 LST was first estimated at 5700 ha. This area was then superimposed on the geographical map with the 3 June image. Three pixels from the 0738 LST image were found to coincide with the same pixels in the 3 June image and a correction was made in the 3 June estimate. This reduced the overall total to 5400 ha. About 4300 ha had burned over the previous $34 \mathrm{~h}$.

An AVHRR 3.7- $\mu \mathrm{m}$ image from 0918 LST showed a total of six areas containing hot spots including the three seen in the earlier morning imagery (Fig. 9). Relative sizes may be indirectly implied utilizing the false color imagery. Winds had increased and the nocturnal inversion had mixed out. Maximum temperatures of the hot spots ranged from 307 to $321 \mathrm{~K}$. Background temperature of adjacent pixels now averaged $289 \mathrm{~K}$, indicating surface diabatic heating. Differencing techniques were used to compare this image with the previous image to determine fire growth and burn direction. Estimation of the areal extent of the hot spots in each of the six areas ranged from 100 to 1100 ha. Again, the image was superimposed onto a geographical map and compared with past image fire pattern. Three of the hot spots showed growth toward the west and southwest. The other three fires were too new to determine burn direction. The corrected image now showed that a total of 7200 ha had burned. Ambiguous pixels were again observed over Big Lake. A visible image from the same AVHRR pass showed smoke rising from all six sites and advecting south-southwest and remaining west of Anchorage.

Higher-resolution OLS visible imagery $(0.3 \mathrm{~km})$ from the DMSP at 0925 LST 5 June showed more clearly the smoke advecting south-southwest from all six hot spot sites seen in the AVHRR 3.7- $\mu \mathrm{m}$ image acquired 7 min earlier (Fig. 10). The WSR-88D radar was able to detect only the two larger smoke plumes. Smoke from the smaller fires may not have risen high enough to be detected by the radar beam $(1830 \mathrm{~m})$. In the two main plumes, reflectivities up to $25 \mathrm{dBZ}$ were measured near the head of the fire. This higher return signal near the head of the fire suggests that the radar detection in this local area was dominated by large particles suspended in the smoke cloud. Downwind, reflectivities ranged between 5 and $10 \mathrm{dBZ}$.

An AVHRR 3.7- $\mu \mathrm{m}$ image from 1349 LST showed that two smaller individual hot spots observed earlier north and east of Big Lake at 0918 LST had merged into one (Fig. 11). By this same time, the intensity of all five hot spots had been reduced, with a maximum brightness temperature of $315 \mathrm{~K}$ observed in the image. This reduction of the maximum temperatures in the hot spots was probably due to overstory obscuration and some smoke. AFS reported that the fire at this time had slowed its forward progress and was burning more in the understory than in the crowns, although there were still some crown fires. The areas of burn delineated in previous passes were now combined with this pass onto a geographical map and any corrections made. All the

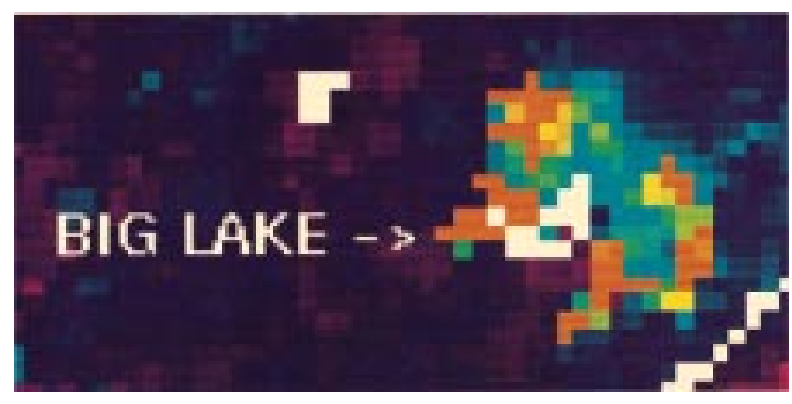

Fig. 11. NOAA AVHRR 3.7- $\mu$ m image, 1349 LST 5 June 1996, showing fire-affected pixels using a false color table (red $=$ hot, blue = cold).

hot spots showed growth to the west and southwest. Estimation of total area burned was 9300 ha. A subsequent pass at 2145 LST (not shown) indicated a total burn area of 11900 ha.

\section{Discussion}

The GOES 3.9- $\mu \mathrm{m}$ imagery provided early detection of the Miller's Reach fire on the night of 3 June when pixels north of Big Lake suddenly showed warming relative to surrounding areas. This was at a time when the fire was still relatively small. The authors estimated the location, intensity, and growth of the Miller's Reach fire real time using a time series of AVHRR 3.7- $\mu \mathrm{m}$ passes interspersed with DMSP imagery. The estimates were then provided to the forest fire decision makers. All of the scenes were cloud free over the fire area. All the passes were corrected for variable sensor noise and registration. All pixels were continuously monitored through the time sequence to determine temporal changes and minimize the inclusion of pixels in which the field of view was only partially occupied by fire in previous passes. Each successive pass was superimposed onto a geographical map using Big Lake and Beaver Lake as the navigational references. Each pixel was numbered. If a new pass showed the same pixel seen in previous images as a hot spot, that pixel was assumed to have been only partially occupied by fire in the previous image. The total burn estimation was then adjusted accordingly. This procedure prohibited the counting of a given area of the fire more than once. Saturated pixels surrounded by other fire-affected pixels were assumed to indicate areas had been completely burned. Figure 12 shows a time series of growth and direction of the fire-affected pixels during an 8 -h period on 5 June utilizing the procedure outlined above.

Table 1 shows a comparison of the fire size identified by satellite to that observed by the AFS, including a final total. While the estimates provided by the AFS may contain errors from the aircraft reconnaissance, the comparison still finds a close match to the information collected in the field quite well.

The difference in the estimation of the fire size com- 


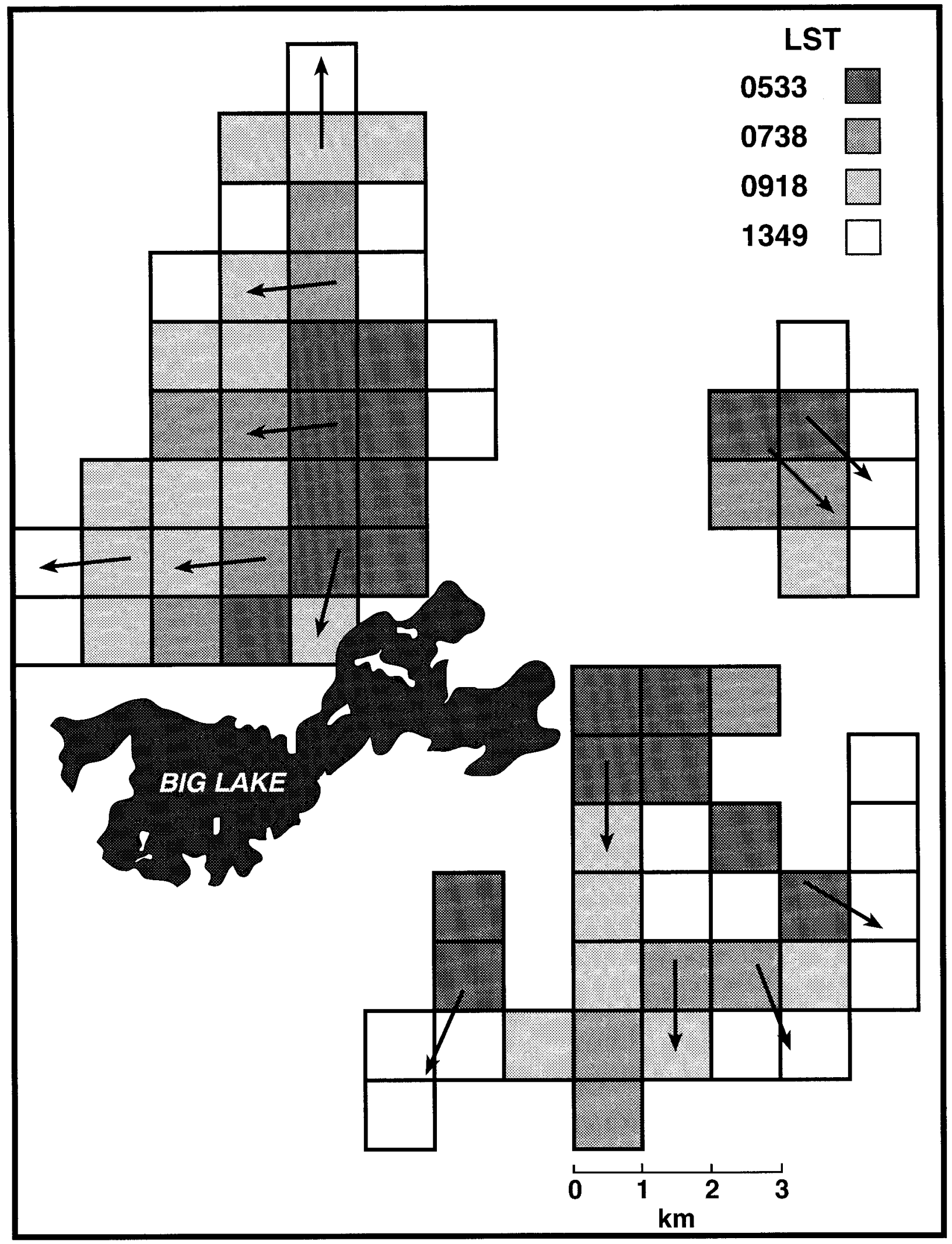

FIG. 12. Time series of overlain fire-affected pixels on geographic map showing growth and direction of Miller's Reach fire for an 8-h period on 5 June 1996. 
TABLE 1. Fire size statistics between satellite and ground observation.

\begin{tabular}{lcc}
\hline \hline Time (LST) & $\begin{array}{c}\text { Satellite } \\
\text { observation } \\
\text { (ha) }\end{array}$ & $\begin{array}{c}\text { AFS } \\
\text { observation } \\
\text { (ha) }\end{array}$ \\
\hline 2034 3 Jun & 900 & 780 \\
2300 3 Jun & & 1335 \\
2300 4 Jun & & 4800 \\
0738 5 Jun & 5400 & 6300 \\
0918 5 Jun & 7200 & 8900 \\
1349 5 Jun & 9300 & 9400 \\
1638 5 Jun & 9700 & 10062 \\
2145 5 Jun & 11900 & 15128 \\
1700 15 Jun & 17400 & 15128 \\
1700 15 Jun & 16475 & \\
\hline
\end{tabular}

* Combined AVHRR and SAR estimate.

paring the AVHRR 3.7- $\mu \mathrm{m}$ data to the AFS estimates (assuming AFS estimates as the base) ranged from 5\% to $15 \%$ with the AVHRR data always overestimating the size. These results are consistent with other studies. The resolution of the AVHRR data is $1.1 \mathrm{~km}$, making it impossible to resolve the location of small fires within a given pixel. The actual temperature values sensed by the satellite can be affected by fuel type and moisture, density of combustibles, obscuration by smoke and clouds, undergrowth, blockage by overstory canopy and terrain, and extent of fire within a pixel. This can make identification of some fire areas difficult and some forest fires even missed.

An attempt was made to improve on the satellite estimation of the total fire size by conducting an analysis using AVHRR 3.7- $\mu \mathrm{m}$ and higher-resolution SAR imagery together. The SAR imagery proved of only limited use. A significant portion of the Miller's Reach fire involved a crown fire that left standing tree trunks and undergrowth. This resulted in a burn area that did not produce an intensity of reflected radiation much different from adjacent untouched forests. However, in those areas where the fire consumption of all the foliage was complete, the SAR imagery provided a distinct return from surrounding forests. Estimation of total fire size using the combined imagery was 16475 ha, an improvement of $8 \%$ over the AVHRR data alone. This technique helps eliminate some overestimation of fire in the AVHRR pixels, but ambiguity between areas of crown fire and surrounding forest still produced results greater than the AFS (15 128 ha) by about $9 \%$.

Relatively high reflectivities (20-25 dBZ) were observed by the WSR-88D radar in the smoke plumes near the head of rapidly moving fires. Firefighters on the scene reported that high winds generated a number of fire storms that moved rapidly through the crowns of the trees and large firebrands were observed. At this time of year, there were large concentrations of cones at the top of the spruce trees. The firestorm sent the cones as firebrands aloft by convection and winds con- tinued to move them downstream a short distance. This scenario can be seen in the radar data.

The WSR-88D radar detected high reflectivities for a distance of only $1.5-2.5 \mathrm{~km}$ from the fire head. The rapid disappearance of the high reflectivities from the radar indicate that the signal was dominated by particles greater than $1 \mathrm{~cm}$ in diameter. An average spruce cone is about $6 \mathrm{~cm}$ long, weighs about $60 \mathrm{~g}$, and has a volume of $12 \mathrm{~cm}^{3}$. A particle with a density of $5 \mathrm{~g} \mathrm{~cm}^{-1}$ would be removed from a smoke plume at an altitude of 1500 $\mathrm{m}$ within a minute. At the rate of the measured winds $\left(20 \mathrm{~m} \mathrm{~s}^{-1}\right)$ at the fire scene, a transport time for the firebrands would be about 1-2 min to drift up to 2.5 $\mathrm{km}$. Thus the combination of strong horizontal winds and the loss of mass of the firebrand by continued burning kept the firebrands within the plume for up to 2.5 $\mathrm{km}$.

AIRS was used to transmit, receive, and display the products described above at the remote fire site. In addition to the satellite and radar, the product suite included the NCEP Eta Model, AVN Model, MRF Model, upper air soundings, observational data, and forecasts.

\section{Summary}

Real-time multisatellite imagery was used to determine the Miller's Reach fire location, intensity, and growth. Utilizing current data techniques and quality control, satellite observations were sufficiently accurate in this case to provide rapid, relatively inexpensive information to decision makers about the fire, especially in the more remote areas. The Doppler radar provided information on smoke plume location and density to agencies concerned with public health downstream. The products derived from the satellite and radar data were made available within $30-40 \mathrm{~min}$ of data receipt. The Internet was used to provide products to a variety of users in and out of Alaska.

Acknowledgments. The authors would like to acknowledge the contributions of several agencies that supplied valuable information and assistance on the evolution of the Miller's Reach fire. This includes the professionals at Alaska Fire Service; the Alaska Department of Natural Resources, Division of Forestry; the Alaska Division of Emergency Services; and the U.S. Forest Service. We are also grateful to CIRA/RAMM, Colorado State University, and especially David Watson for his expert assistance in providing GOES-9 imagery and diagnostic products.

\section{REFERENCES}

Alaska Department of Natural Resources, 1996: Miller's Reach \#2 fire review. 49 pp. [Available from Department of Natural Resources, 3601 C Street, 12th Floor, Anchorage, AK 99503.]

Chuvieco, E., and M. P. Martin, 1994: A simple method for fire growth mapping using AVHRR channel 3 data. Int. J. Remote Sens., 15, 3141-3146. 
Dragomir, J. H., W. Sparkman, and H. L. Kelley, 1997: Alaska Incident Response System forecast support and development in 1996. Preprints, 13th Int. Conf. on Interactive Information and Processing Systems for Meteorology, Oceanography, and Hydrology, Long Beach, CA, Amer. Meteor. Soc., 377-379.

Henderson-Sellers, A., 1984: Satellite Sensing of Cloudy Atmosphere: Observing the Third Planet. Taylor and Francis, $340 \mathrm{pp}$.

Kasischke, E. S., L. L. Bourgeau-Chavez, N. H. F. French, P. Harrell, and N. L. Christensen, 1992: Initial observations on the use of SAR imagery to monitor wildfires in boreal forests. Int. J. Remote Sens., 13, 3495-3501.

Kaufman, Y. J., C. J. Tucker, and I. Fung, 1990: Remote sensing of biomass burning in the Tropics. J. Geophys. Res., 95, 99279939.

Kidwell, K. B., 1995: NOAA polar orbiter data users guide (NOAA TIROS 6-14). NOAA NESDIS Rep., 386 pp. [Available from NESDIS, Federal Office Building 3, Washington DC 20233.]
Klazura, G. E., and D. A. Imy, 1993: A description of the initial set of analysis products available from the NEXRAD WSR-88D system. Bull. Amer. Meteor. Soc., 74, 1293-1311.

Lee, T. F., and P. M. Tag, 1990: Improved detection of hot spots using the AVHRR 3.7- $\mu \mathrm{m}$ channel. Bull. Amer. Meteor. Soc., 71, $1722-1730$

Probert-Jones, J. R., 1962: The radar equation in meteorology. Quart. J. Roy. Meteor. Soc., 88, 485-495.

Robinson, J. M., 1991: Fire from space: Global fire evaluation using infrared remote sensing. Int. J. Remote Sens., 12, 3-24.

Simpson, J. J., and S. R. Yhann, 1994: Reduction of noise in AVHRR channel 3 data with minimum distortion. IEEE Trans. Geosci. Remote Sens., 32, 315-328.

Weaver, J. F., J. F. Purdom, and T. L. Schneider, 1995: Observing forest fires with the GOES-8 3.9- $\mu \mathrm{m}$ imaging channel. Wea. Forecasting, 10, 803-808. 